\title{
The effects of Hydration on the DC Breakdown Strength of Polyethylene Composites Employing Oxide and Nitride Fillers
}

\author{
I. L. Hosier, M. Praeger, A. S. Vaughan and S. G. Swingler \\ Tony Davis High Voltage Laboratory. \\ University of Southampton, \\ Southampton, SO17 1BJ, UK
}

\begin{abstract}
Particle dispersion, water absorption/desorption and electrical breakdown behavior were studied in a range of polyethylene composites having a common matrix morphology. Three different conditioning routes (dry, ambient and wet) were used to vary the absorbed water content. Systems employing oxide fillers (silica and alumina) were found to have poor or intermediate levels of particle dispersion and could absorb/desorb significant amounts of water. Consequently, they required drying to provide breakdown strengths comparable to that of the host matrix. Systems based on calcined silica exhibited reduced water absorption and provided improved breakdown strength after ambient conditioning, despite having an identical dispersion to those utilizing untreated silica. Composites employing nitride fillers (silicon nitride and aluminum nitride) were found to have good or intermediate levels of particle dispersion. These absorbed far less water and hence provided breakdown strength values comparable to that of the host matrix following ambient conditioning. Their breakdown strength was degraded after wet conditioning with both exhibiting similar breakdown strengths despite there being a large difference in the level of particle dispersion between the two fillers. In composites based upon a hydrophobic host matrix, water absorption is largely determined by particle surface chemistry and, although the above results are presented in terms of water absorption, we suggest that changes in this characteristic can be interpreted as a proxy for changed surface chemistry. The results suggest that surface chemistry is at least as important as particle dispersion in determining the electrical breakdown strength.

Index Terms - Composites, water absorption, morphology, dielectric breakdown strength
\end{abstract}

\section{INTRODUCTION}

NANOCOMPOSITES, where an inert filler is incorporated into a polymeric matrix, provide an effective means of improving the mechanical performance of existing polymeric materials [1] and, consequently, this strategy is widely employed in roles where high strength and low weight are important; for example, in aerospace and automotive applications. However, the situation regarding the electrical properties of composites is far from clear, since many studies report contradictory results. This lack of consistency remains a major barrier to their commercial exploitation in high voltage insulation systems. For instance, in one report on epoxy composites [2], the electrical breakdown strength was hardly influenced by either nano- or micro-silica, while more recent investigations revealed improvements in breakdown strength, provided the filler loading was not too high $[3,4]$. In another notable study on epoxy based systems [5] the

Manuscript received on 5 January 2017, in final form 27 April 2017, accepted 22 May 2017. Corresponding author: I. L. Hosier. addition of untreated nanoparticles increased the level of water absorption; crucially, measurements of glass transition temperatures indicated that the water was stored in shells surrounding each particle and not held in the host material.

In the more relevant combination of polyethylene with silica, the literature also presents a mixed picture; for example, in one study [6], composites employing vinyl silane treated nano-silica displayed improved AC breakdown strength, provided they were carefully dried to eliminate the effects of absorbed water. Similarly [7], improved DC breakdown strength was reported in a series of dried XLPE/silica composites. In contrast to these findings, other work [8-10] has shown that considerable absorbed water can be present in such composites and has indicated a reduction in DC breakdown strength with increasing filler loading. Similarly, reduced AC breakdown strength has been reported [11] in a series of silica/XLPE nanocomposites that had been exposed to ambient and wet conditions. The effects of silica 
within various host polymers was considered in another report [12] and it was observed that some combinations of host matrix and filler provided increased breakdown strength whilst others showed decreased breakdown strength. Finally, in a study of polystyrene/silica nanocomposites, DC breakdown strength was again observed to fall with increasing filler loading [13].

Whilst composites utilizing nano-silica have received much attention in the literature owing to the fact that silica is chemically inert and cheap to buy, other materials have also been studied; silicon nitride, for example, provides improved thermal conductivity [14] and was reported to provide improved breakdown strength when used with a polypropylene host [15]. Similarly, increases in AC breakdown strength in epoxy/alumina systems have been reported [16, 17] while, in another study [18], absorbed water was reported to reduce the electrical breakdown strength of a series of alumina/ethylene-co-butene acrylate composites. Other notable papers on alumina [19, 20] and aluminum nitride $[21,22]$ focus on their improved thermal conductivity, which could potentially increase short term overload ratings if such composites were to be employed in a high voltage cable system [23]. In all these studies, two key variables are thought to be important in determining breakdown performance - particle dispersion and water absorption.

First, consider the role of particle dispersion - whilst morphological data are not provided in all publications, where this information is included, poor particle dispersion is said always to result in degraded performance [9, 10, 13] whilst good dispersion, obtained for example through sol-gel processing, always results in improved performance $[4,6,7]$ or no change [2]. Indeed, many other examples exist in the literature to indicate that particle size and breakdown strength are inversely related. In the case of a range of systems containing 5\% silica in an XLPE host matrix, the inclusion of $5 \%$ of the micron-sized filler markedly reduced the breakdown strength whilst the addition of $5 \%$ of nano-filler gave a level of performance that was comparable to that of unfilled XLPE [6]. Comparable behavior was seen in montmorillonite-filled polyethylene blends [24]. Andritsch et al. [25] considered the effect of particle size on the breakdown strength of epoxy-based systems containing $10 \%$ of hexagonal boron nitride and reported a monotonic increase in breakdown strength with decreasing particle size over the range $5 \mu \mathrm{m}$ to $70 \mathrm{~nm}$. Recently, the effect of processing conditions on the dispersion and breakdown behavior of composites based upon alumina and polyethylene has been reported [26]. This work concluded that while large agglomerates had an adverse effect on breakdown strength, smaller agglomerates $(<3 \mu \mathrm{m})$ had no significantly negative impact. Clearly, reducing particle aggregation and obtaining good dispersion are important for achieving the maximum level of electrical breakdown strength in a composite, but the critical particle size necessary to give increased performance is unclear.

Second, consider the effects of water absorption - the few studies that do exist indicate that absorbed water tends to reduce breakdown strength [9, 10, 18], while thorough drying can improve matters [6, 7]. It is therefore important to eliminate absorbed water through drying and/or by reducing the concentration of surface hydroxyl groups on particle surfaces, which can bind water molecules $[1,11]$. One way to reduce the level of surface hydroxyl groups in silica is through functionalization, which has the added advantage of improving compatibility with the host matrix [8-10]. While both effects are likely to be beneficial, which mechanism is dominant (direct changes in surface chemistry or consequential changes in dispersion) remains uncertain. Alternatively, a nitride rather than an oxide-based filler could be used dramatically to change the surface chemistry. Whilst in theory this is appealing, in silicon nitride, for example, an oxynitride layer quickly forms on exposure to air or water even at room temperature, such that the actual surface chemistry contains hydroxyl along with amine groups [27]. Conversely, exposure to very high temperatures is required to achieve this in aluminum nitride [28].

During calcination [29-31], silica is thermally treated to modify its surface chemistry. Annealing silica at temperatures below $500{ }^{\circ} \mathrm{C}$ results in the removal of bound water and partial removal of covalently bonded hydroxyl groups but, at such temperatures, strained siloxane bridges remain, which hydrolyze rapidly upon subsequent exposure to water. However, if calcination is performed above $900{ }^{\circ} \mathrm{C}$ [29], the strained siloxane bridges relax with the effect that the silica becomes hydrophobic and stable against hydrolysis for several years of contact with water [30]. It has been shown [31] that calcination reduces the level of water uptake and, hence, results in improved dielectric properties and reduced sensitivity to variable environmental conditions compared to composites containing untreated silica.

While it is possible to compare breakdown data from diverse studies and to attempt to extract general conclusions, the validity of this is always open to the criticism that matrix polymers, processing methodologies and measurement protocols vary from laboratory to laboratory. Here we obviate this by comparing the effect of different fillers in a single host matrix where identical procedures have been used throughout to prepare samples and test the various systems. The specific objectives of this study were:

(a) To examine the relative importance of particle dispersion and particle surface chemistry on the breakdown behavior of the resulting composites.

(b) To examine the effect of different particle chemistries on the accumulation of water at particle surfaces.

All the composites considered here were based upon a polyethylene blend composed of high density polyethylene within a low density polyethylene matrix. Previous work has shown that such blend systems are ideally suited to the objectives of this study, for the following reasons. First, when isothermally crystallized, the influence of the nanoparticles on the matrix morphology is clearly revealed [8]. Second, the two-stage crystallization process that occurs when such systems are crystallized isothermally means that breakdown behavior is independent of spherulite size [32], such that variations in nucleating efficiency from nanofiller to nanofiller are eliminated. This is in sharp contrast to what happens in a single component polymer matrix, where differences in surface chemistry and structure can affect nucleation of the polymer, change its morphology and, therefore, have an indirect effect on 
macroscopic properties [33]. Consequently, any changes in behavior that are observed here are not associated with indirect effects associated with variations in matrix morphology. Rather, the effects we report should be directly related to the presence of the particles themselves $[34,35]$. In the current investigation, the effects of morphology, conditioning (i.e. exposure to water) and particle dispersion on dielectric breakdown strength are reported.

\section{EXPERIMENTAL}

\subsection{MATERIALS AND CALCINATION}

A polymer blend composed of 20 wt. \% high density polyethylene (HDPE, BP Rigidex HD5813EA) plus 80 wt. \% low density polyethylene (LDPE, ExxonMobil, LD100BW) was prepared by melt blending in a Thermo Scientific PolyLab QC twin screw mixer $\left(160^{\circ} \mathrm{C}\right.$; speed $40 \mathrm{rpm}$; measured torque 8-12 $\mathrm{N} \mathrm{m}$ ) for $20 \mathrm{~min}$, after which time, the product was removed and pressed into sheets using a hydraulic press. Differential scanning calorimetry (DSC) was then used to verify the uniformity of the product.

Silicon nitride $\left(\mathrm{Si}_{3} \mathrm{~N}_{4}\right.$, spherical $\left.\sim 50 \mathrm{~nm}\right)$, silica $\left(\mathrm{SiO}_{2}, 10-20\right.$ $\mathrm{nm})$, aluminum nitride (AlN, $100 \mathrm{~nm})$ and alumina $\left(\mathrm{Al}_{2} \mathrm{O}_{3},<\right.$ $50 \mathrm{~nm}$ ) were all obtained from Sigma Aldrich - the quoted dimensions are those provided by the supplier. A portion of the as-supplied silica was held at $1050{ }^{\circ} \mathrm{C}$ [29] for $10 \mathrm{~h}$ in dry nitrogen; the effectiveness of this calcination process was confirmed by infrared spectroscopy as a clear absence of hydroxyl groups [31] and this treated filler is subsequently referred to as $\mathrm{SiO}_{2}(\mathrm{C})$. All other fillers were used as supplied.

\subsection{NANOCOMPOSITE PREPARATION}

A total of 10 composites (Table 1) with nominal filler contents of 5 and 10 wt. \%, plus an unfilled control sample, were prepared from the polyethylene blend and the various particles described above. A modified solvent blending route involving dissolution of the polymer blend in xylene and dispersion of the particles in isopropyl alcohol (IPA) was used throughout $[31,34,35]$. This approach was adopted here to alleviate difficulties associated with the direct dispersion of polar particles into a non-polar solvent such as xylene. Specifically, $5 \mathrm{~g}$ of the polymer blend was dissolved in $50 \mathrm{ml}$ of boiling xylene while the required mass of particles was dispersed in $10 \mathrm{ml}$ of IPA and sonicated for 5 min using a Hielscher UP200S probe sonicator, stirred and sonicated for a further $5 \mathrm{~min}$. The xylene/polymer solution was removed from the heat, allowed to gel slightly and the powder/IPA solution was immediately added; stirring was maintained until

Table 1. Blends used in these investigations.

\begin{tabular}{|c|c|c|c|}
\hline Blend & $\begin{array}{l}\text { Nominal filler } \\
\text { content and type }\end{array}$ & $\begin{array}{l}\text { Quoted particle } \\
\text { size }(\mathrm{nm})\end{array}$ & $\begin{array}{c}\text { Measured } \\
\text { residue content } \\
(\text { wt. } \%)\end{array}$ \\
\hline Control & - & - & $<0.1$ \\
\hline SiN05 & 5 wt. $\% \mathrm{Si}_{3} \mathrm{~N}_{4}$ & 50 & $4.2 \pm 0.1$ \\
\hline SiN10 & 10 wt. $\% \mathrm{Si}_{3} \mathrm{~N}_{4}$ & & $8.6 \pm 0.2$ \\
\hline $\mathrm{SiO} 05$ & 5 wt. $\% \mathrm{SiO}_{2}$ & $10-20$ & $4.7 \pm 0.4$ \\
\hline $\mathrm{SiO} 10$ & 10 wt. $\% \mathrm{SiO}_{2}$ & & $8.8 \pm 0.6$ \\
\hline AlN05 & 5 wt. $\%$ AlN & 100 & $5.4 \pm 0.4$ \\
\hline AlN10 & 10 wt. $\%$ AlN & & $8.9 \pm 0.3$ \\
\hline $\mathrm{AlO} 05$ & 5 wt. $\% \mathrm{Al}_{2} \mathrm{O}_{3}$ & $<50$ & $5.2 \pm 0.3$ \\
\hline $\mathrm{AlO} 10$ & 10 wt. $\% \mathrm{Al}_{2} \mathrm{O}_{3}$ & & $9.0 \pm 0.3$ \\
\hline CAL05 & 5 wt. $\% \mathrm{SiO}_{2}(\mathrm{C})$ & - & $3.9 \pm 0.2$ \\
\hline CAL10 & 10 wt. $\% \mathrm{SiO}_{2}(\mathrm{C})$ & & $8.4 \pm 0.1$ \\
\hline
\end{tabular}

the mixture had thickened to a waxy solid. To remove all solvent residues, this product was dried for $24 \mathrm{~h}$ in a fume cupboard, cut into small cubes, then left a further $24 \mathrm{~h}$ and, finally, pressed at $160{ }^{\circ} \mathrm{C}$ into sheets of the required thickness. These were crystallized for $1 \mathrm{~h}$ in an oil bath held at $115{ }^{\circ} \mathrm{C}$ and were then quenched into water [32]. To ascertain the true filler concentration, three separate samples of each system were taken and heated to $600{ }^{\circ} \mathrm{C}$ in a thermogravimetric analyzer (TGA - Perkin Elmer Pyris 1) under air.

\subsection{CONDITIONING}

Ambient conditioning was performed by leaving samples for at least $14 \mathrm{~d}$ to equilibrate with the laboratory environment $\left(19 \pm 2{ }^{\circ} \mathrm{C}, 55-80 \% \mathrm{RH}\right)$. After this initial conditioning period in the laboratory, batches of specimens were further conditioned by storage under vacuum for $14 \mathrm{~d}$ (subsequently referred to as dry samples) or immersion in water for $14 \mathrm{~d}$ (subsequently referred to as wet samples). After conditioning, the weight gain (wetting) or loss (drying) was determined using a digital balance (uncertainty $\pm 0.02 \%$ ), to ascertain the mass of water absorbed/desorbed as a consequence of the imposed conditioning process.

\subsection{CHARACTERISATION}

The morphology of the resulting materials was determined by scanning electron microscopy (SEM). All systems were etched for $4 \mathrm{~h}$ in a solution of $1 \%$ potassium permanganate in an acid mixture composed of 5:2:1 of sulfuric acid : phosphoric acid : water, according to established procedures [36]. Samples were then mounted onto aluminum SEM stubs, gold coated and examined at $15 \mathrm{kV}$ in a JEOL JSM6500F high resolution field emission gun SEM.

The effect of material composition (filler and loading level) and conditioning (ambient, dry or wet) on DC breakdown strength was investigated using samples $0.1 \mathrm{~mm}$ in thickness. These were placed between opposing $6.3 \mathrm{~mm}$ ball bearing electrodes in silicone fluid (Dow Corning 200/20CS) and an increasing DC voltage $(100 \mathrm{~V} / \mathrm{s})$ was applied until the sample failed; the measured breakdown voltage and the thickness of the specimen at the breakdown site were then used to determine the breakdown strength. For each composite, this procedure was repeated twenty times at different locations and the resulting data were analyzed assuming a two parameter Weibull distribution.

\section{RESULTS}

\subsection{FILLER CONCENTRATION}

The residue (filler) contents from the TGA measurements were found to fall close to the expected values (Table 1), albeit some loss of filler inevitably occurs during sample preparation.

\subsection{WATER ABSORPTION AND DESORPTION}

Figure 1 shows the change in mass after dry or wet conditioning of the various composites considered in this investigation. Comparing 5 and 10 wt. \% filler content, the extent of water absorption/desorption is approximately doubled in the $10 \mathrm{wt}$. \% systems relative to the $5 \mathrm{wt}$. \% systems, which strongly supports conclusions presented 


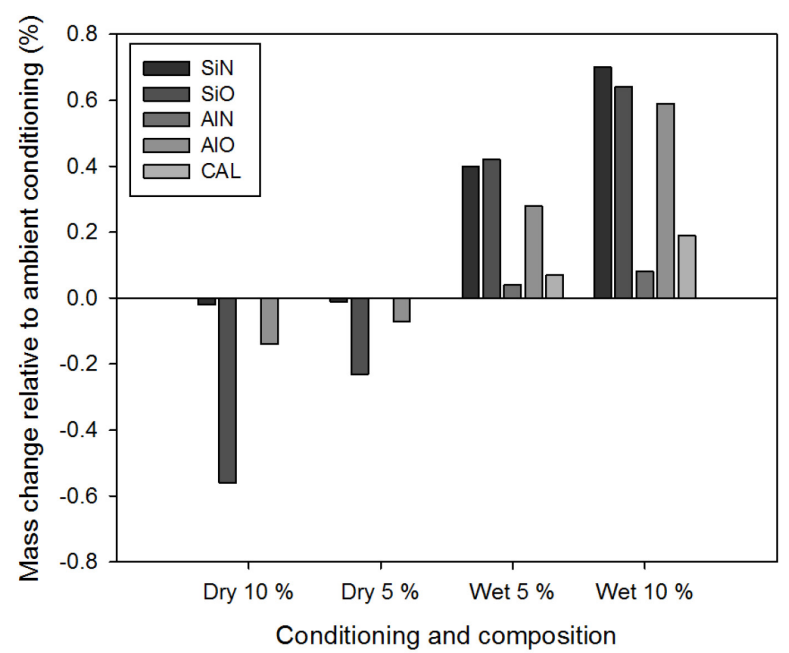

Figure 1. Water absorption/desorption results for dry and wet conditioning relative to ambient (uncertainty $\pm 0.02 \%$ ).

elsewhere [8] that water absorption in polyethylene composites is associated with diffusion of water to, and its subsequent accumulation at, particle/matrix interfaces. SiOxx shows the greatest level of water absorption/desorption and has an intermediate level of hydration following ambient conditioning (as evinced by the observation that water can be extracted by drying or added by wetting). The data presented here are consistent with those in pertinent literature [9-11]. AlOxx exhibits a similar form of behavior, albeit with a reduced level of water absorption/desorption [18]; these systems also have an intermediate level of hydration following ambient conditioning. In contrast, SiNxx and AlNxx are dry when ambient conditioned (as evinced by little or no loss of water following dry conditioning); however, it is possible to "force" significant amounts of water into SiNxx through wet conditioning (i.e. immersion in water). Previously [27, 34], in systems based upon $\mathrm{Si}_{3} \mathrm{~N}_{4}$, this process was discussed in terms of the progressive formation of an oxynitride layer, which would be absent in AlNxx [28, 35]. Finally, CALxx behaves very differently from SiOxx; it is dry following ambient conditioning and absorbs only a small amount of water even on immersion in water [31]. Thus, each of the five nanocomposite formulations considered here behaves very differently in terms of water absorption and desorption, effects we associate with variations in the particle surface chemistry.

\subsection{MORPHOLOGY}

Figure 2 contains two SEM micrographs showing the morphology of $\mathrm{SiO} 10\left(10\right.$ wt. $\left.\% \mathrm{SiO}_{2}\right)$. From Figure 2a, it is evident that while the silica is uniformly distributed throughout the sample, it is, nevertheless, present in a range of agglomerated structures that vary in size up to tens of micrometers $[8,10]$. The higher magnification SEM micrograph in Figure $2 b$ shows a number of such agglomerated structures, from which it is evident that these are composed of primary particles whose scale is commensurate with the size range indicated by the supplier. In both of these micrographs, evidence of the banded spherulitic texture of the matrix can be seen; this is in line with that seen in the unfilled
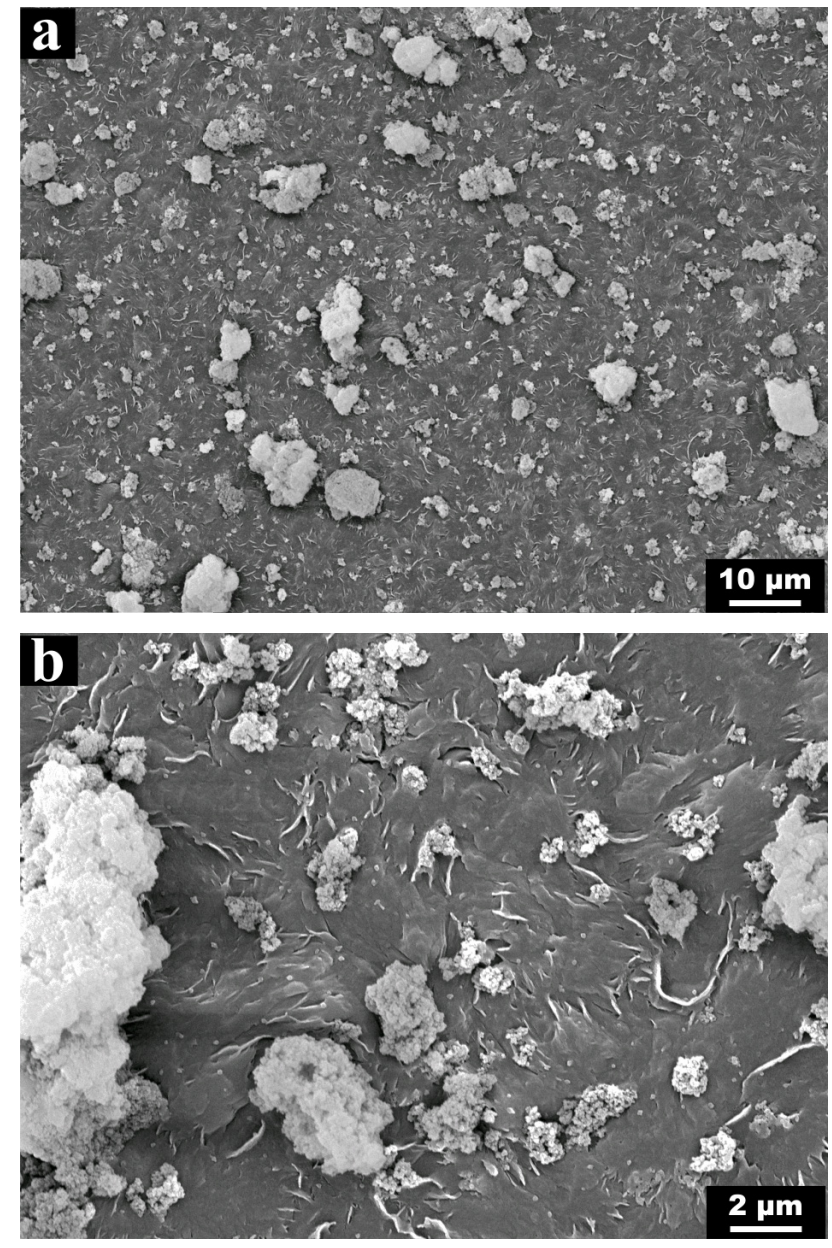

Figure 2. SEM micrographs of SiO10 (a) low magnification (b) high magnification.

polymer $[10,34]$ but, as reported previously, is somewhat perturbed by the inclusion of the nanofiller.

Figure 3 shows two equivalent SEM micrographs of SiN10 (10 wt. $\% \mathrm{Si}_{3} \mathrm{~N}_{4}$ ). The low magnification image (Figure 3a) reveals a uniform distribution of silicon nitride throughout the matrix with relatively few agglomerates (Figure $3 b$ ). Comparing Figures 2 and 3 reveals very different particle dispersions and, although the supplier indicates that the primary particle size is less in the silica (Table 1), within the composite (and as supplied), the extent of agglomeration is clearly much less severe in the silicon nitride-based system [15].

Low magnification SEM micrographs obtained from AlO10, ALN10 and CAL10 are shown in Figure 4. All three of these images were obtained at the same magnification as used for Figures 2a and 3a above. Evidently, the change in the chemistry of the filler and the variability in the quoted particle size is not immediately obvious in these images since, as in Figure 2, the dominant characteristic of all these images is a uniform dispersion of the inorganic phase, which is present in a range of agglomerated structures within a generally spherulitic matrix. In particular, comparison of Figure $4 \mathrm{c}$ with Figure 2a indicates that calcination appears to have had little effect on the overall morphology of the silica, an assertion that is confirmed by direct examination of each particulate system prior to production of the final system. This observation is 

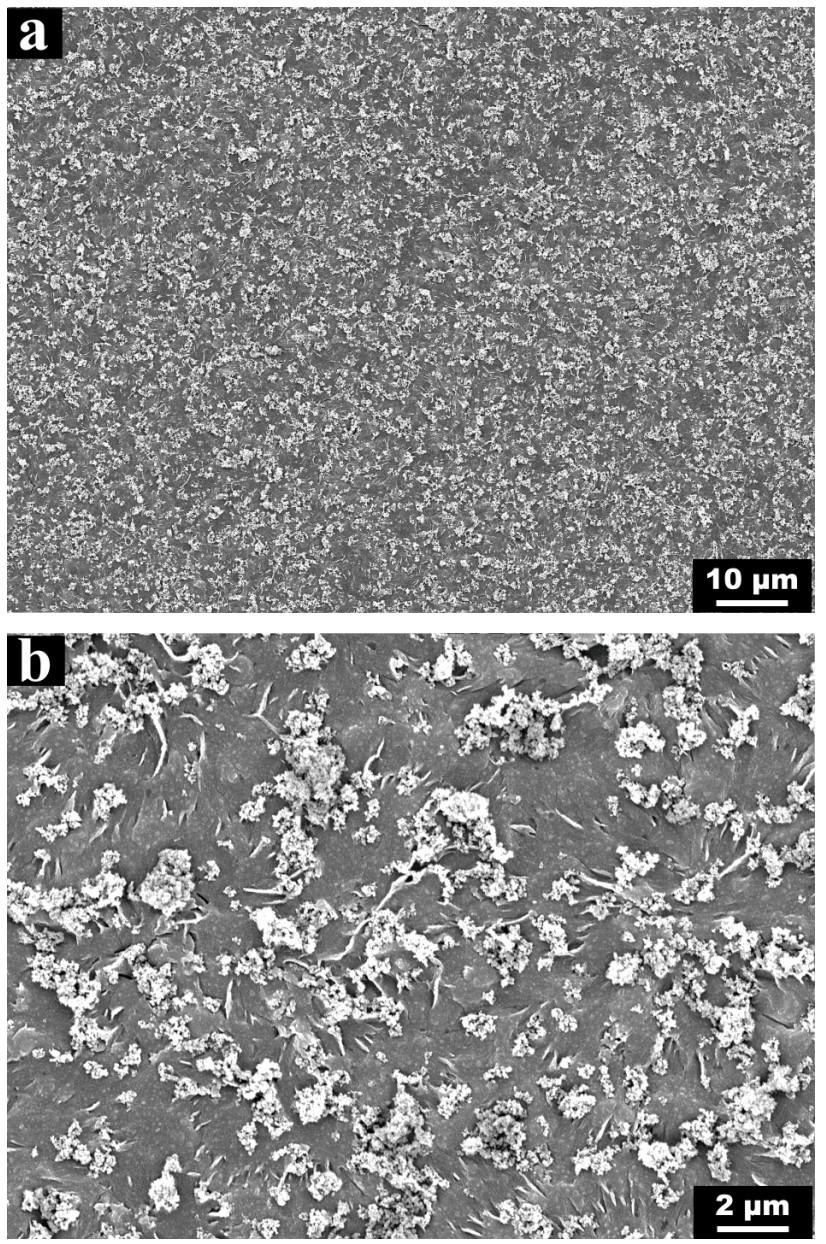

Figure 3. SEM micrographs of SiN10 (a) low magnification (b) high magnification.

also consistent with previous studies of the effect of thermal processing on the structure of nanoparticles. In the case of annealing a zirconia aerogel, even after heating at $1000^{\circ} \mathrm{C}$, the particle size was found to be no larger than $30 \mathrm{~nm}$ [37]. For zinc oxide annealed at different temperatures, Ba-Abbad reported that the particle size increased from $20 \mathrm{~nm}$ at $400{ }^{\circ} \mathrm{C}$ to $41 \mathrm{~nm}$ at $600{ }^{\circ} \mathrm{C}[38]$.

However, higher magnification images reveal subtle differences between AlOxx and AlNxx. In AlO10 (Figure 5a), the observed micron scale inclusions are clearly composed of aggregates of much smaller $(<100 \mathrm{~nm})$ particles, the size of which is consistent with the particle size quoted in Table 1. In contrast, the majority of the larger objects in AIN10 (Figure 5b) appear to be single micron-scale particles [21], a change which is reflected in the larger average quoted particle size (Table I). This observation may explain the apparently reduced fill density in Figure $4 \mathrm{~b}$ relative to Figure $4 \mathrm{a}$; in AlNxx, a significant fraction of the filler is present in isolated larger particles, resulting in proportionately fewer smaller scale particles. Further supporting evidence for this can be inferred from the matrix texture in Figure $4 \mathrm{~b}$ which, being composed of better developed spherulites, indicates reduced nucleation (i.e. reduced polymer/nanoparticle interactions). Thus, the dispersion in AlNxx can be said to be worse than that of AlOxx, despite both materials appearing to fall
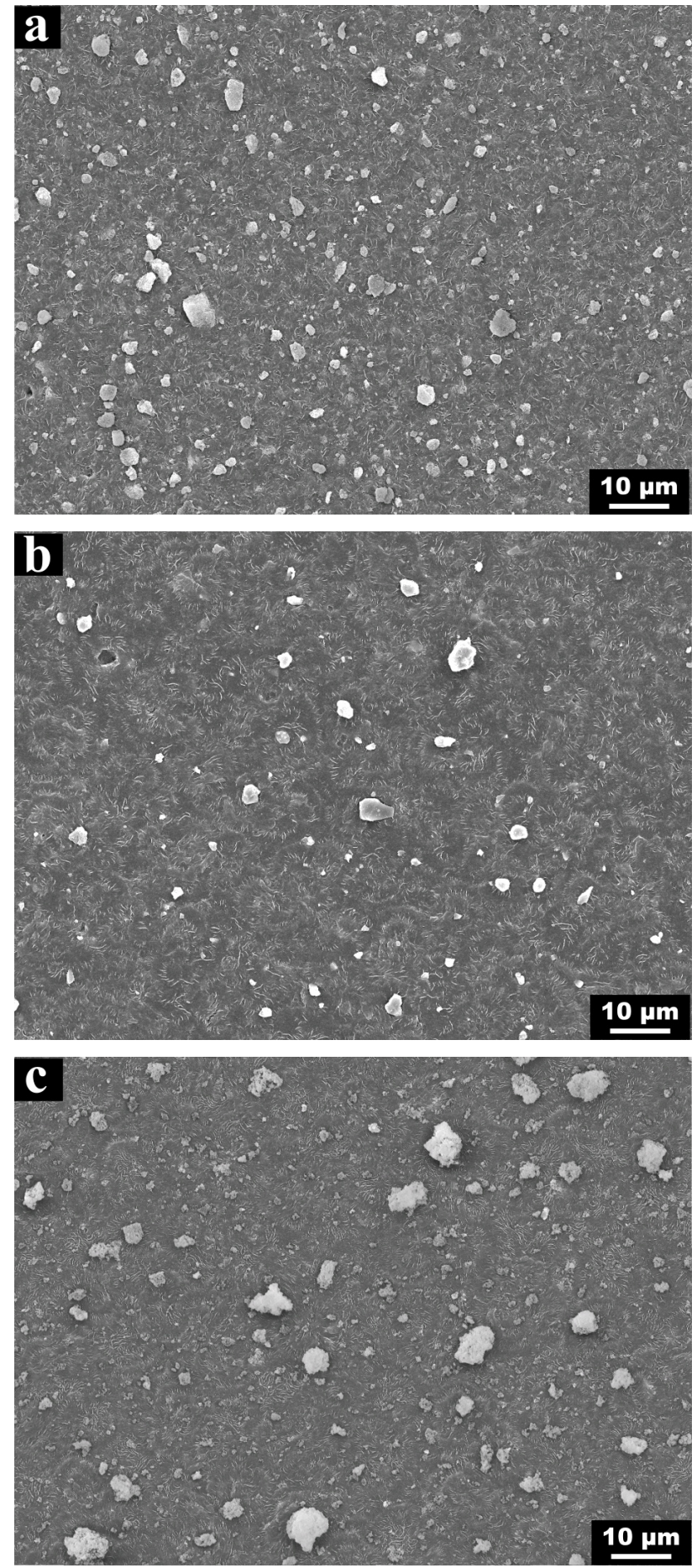

Figure 4. Low magnification SEM micrographs of (a) AlO10 (b) AlN10 (c) CAL10.

somewhere between the two extremes of SiOxx (much aggregation) and SiNxx (little aggregation).

\subsection{BREAKDOWN STRENGTH}

From the morphological data presented above and from earlier detailed DSC studies [34, 35], the inclusion of the various fillers only has a minor influence on matrix morphology and such subtle variations have been shown to have no influence on electrical breakdown strength [32]. However, in all systems, the filler is present in various 

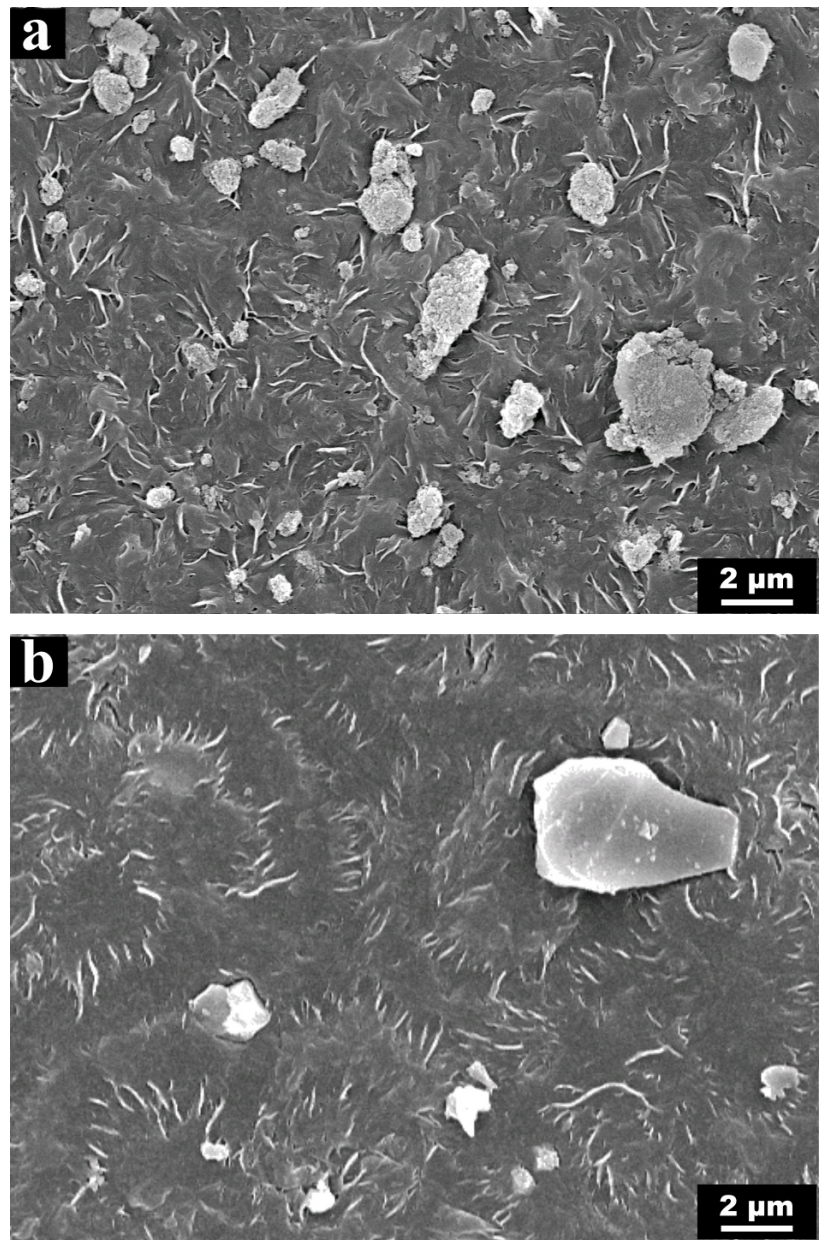

Figure 5. High magnification SEM micrographs of (a) AlO10 (b) AlN10.

agglomerated forms but the systems based upon silicon nitride are markedly different from all the others in that they contain no large agglomerates. Such variations in dispersion and aggregation state might therefore be expected to be reflected in the various systems' breakdown behavior.

Consider, first, the behavior of samples subjected to ambient conditioning - that is, samples in equilibrium with the laboratory environment. Figure 6a contains relevant Weibull plots ( $95 \%$ confidence bounds omitted for clarity) whilst the second column of Table 2 contains derived numerical data and confidence bounds on the scale parameters. Considering the oxide based fillers, it is evident that $\mathrm{SiO} 05, \mathrm{SiO} 10, \mathrm{AlO} 05$ and AlO10 all provide breakdown strengths significantly lower than that of the host polymer; the breakdown strength decreases as the filler loading level increases, as noted elsewhere [9, 10, 13]. Within this group, AlOxx always outperforms SiOxx and reference to Figure 1 suggests that the ambient systems based upon $\mathrm{Al}_{2} \mathrm{O}_{3}$ absorb less water (i.e. subsequent vacuum drying results in less water being extracted). Considering the nitride based fillers, SiN05 and SiN10 show statistically the same breakdown strength as the host polymer whereas that of ALN05 and ALN10 exhibit a small decrease in breakdown strength which is just outside the 95\% confidence bounds in the scale parameters. Presumably, this is due to the presence of the micron-sized particles (see Figure 5b) [26]. Finally, as indicated in Figure 6a, CAL05
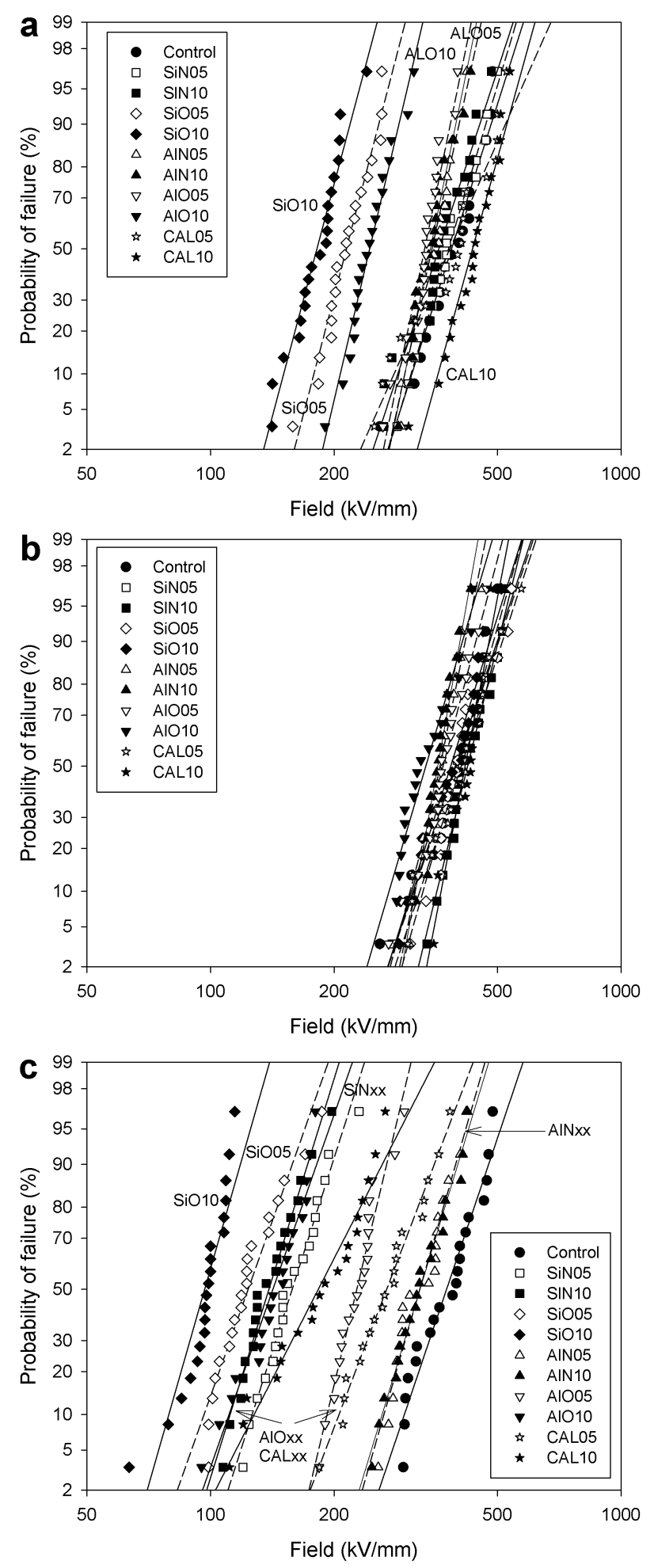

Figure 6. Weibull plots of nano-composites following (a) ambient conditioning (b) dry conditioning (c) wet conditioning.

shows statistically the same breakdown strength as the host polymer whilst the scale parameter of CAL10 is increased.

Whilst dispersion clearly does influence the measured breakdown strength, water absorption appears far more significant here, as highlighted by the following two examples. Firstly, the breakdown strength of SiN10 (containing wt. $10 \%$ of the fine-scale and well-dispersed $\mathrm{Si}_{3} \mathrm{~N}_{4}$ ) is much lower than that of CAL10 (which contains 10 
Table 2. DC breakdown results (typical uncertainty $\pm 20 \mathrm{kV} / \mathrm{mm}$ ).

\begin{tabular}{l|c|c|c}
\hline Blend & $\begin{array}{c}\text { Ambient } \\
\text { conditioning } \\
\mathrm{kV} / \mathrm{mm}(\beta)\end{array}$ & $\begin{array}{c}\text { Dry } \\
\text { conditioning } \\
\mathrm{kV} / \mathrm{mm}(\beta)\end{array}$ & $\begin{array}{c}\text { Wet } \\
\text { conditioning } \\
\mathrm{kV} / \mathrm{mm}(\beta)\end{array}$ \\
\hline Control & $416 \pm 30(7.7)$ & $425 \pm 32(8.0)$ & $408 \pm 32(6.8)$ \\
SiN05 & $409 \pm 30(7.0)$ & $431 \pm 34(6.7)$ & $172 \pm 14(6.0)$ \\
SiN10 & $389 \pm 30(7.0)$ & $450 \pm 27(8.5)$ & $150 \pm 12(6.2)$ \\
SiO05 & $228 \pm 14(8.6)$ & $431 \pm 30(6.7)$ & $135 \pm 12(5.2)$ \\
SiO10 & $194 \pm 12(8.1)$ & $414 \pm 30(7.3)$ & $102 \pm 7(11.0)$ \\
AlN05 & $366 \pm 19(10.1)$ & $382 \pm 14(9.6)$ & $348 \pm 24(7.5)$ \\
AlN10 & $362 \pm 18(9.3)$ & $373 \pm 15(11.9)$ & $350 \pm 26(7.0)$ \\
AlO05 & $349 \pm 17(11.0)$ & $393 \pm 24(8.4)$ & $241 \pm 14(8.1)$ \\
AlO10 & $259 \pm 15(8.4)$ & $360 \pm 25(7.1)$ & $154 \pm 12(7.4)$ \\
CAL05 & $425 \pm 42(5.6)$ & $442 \pm 34(6.5)$ & $295 \pm 26(5.6)$ \\
CAL10 & $463 \pm 29(9.1)$ & $436 \pm 20(13.1)$ & $207 \pm 23(4.8)$ \\
\hline
\end{tabular}

wt. \% of the highly agglomerated $\mathrm{SiO}_{2}(\mathrm{C})$ ). Secondly, $\mathrm{SiO} 10$ and CAL10 are structurally equivalent (c.f. Figure $2 \mathrm{a}$ and Figure $4 \mathrm{c}$ ) but we find that the former has a breakdown strength of $\sim 195 \mathrm{kV} / \mathrm{mm}$, while the latter has a breakdown strength of $\sim 460 \mathrm{kV} / \mathrm{mm}$. Taken together, it would seem from these data that particle dispersion is not the dominant factor in determining breakdown performance but, rather, it would appear that surface chemistry (which here manifests itself as differing interactions with environmental water) plays a more important role, as in the case of other dielectric properties [8$11,13,31,34,35]$.

Consider, now, the effect of dry conditioning in vacuum which, from Figure 1, extracts differing amounts of water from the different systems. In the unfilled control sample, the breakdown strength (see Table 2) is nominally increased after dry conditioning and reduced following wet conditioning. Since all of these values fall within the uncertainties (Table 2), we conclude that the behavior of the unfilled polymer is invariant to the imposed water conditioning protocol $[39,40]$. Following dry conditioning (Figure 6b, Table 2) all of the nanocomposites display a breakdown strength ranging between 360 and $450 \mathrm{kV} / \mathrm{mm}$, values that are broadly comparable to the unfilled host polymer; as above, a reduction in breakdown strength is seen in the systems containing AlNxx, presumably due to the included micron-scale particles. In the case of the oxide based nanocomposites, SiOxx and AlOxx, the breakdown strength is significantly improved after drying $[6,7]$, compared with ambient conditioning; Figure 1 shows that this treatment results in a significant quantity of water being extracted. The remaining systems show little change in breakdown strength relative to the ambientconditioned samples, which correlates with little or no water being extracted on vacuum drying (see Figure 1).

Wet conditioning (Figure 6c) has a negative influence on the electrical breakdown strength, as reported in the literature for a number of different composites [9-11, 18, 41], some more so than others. AlOxx, SiNxx and SiOxx show a progressively greater fall in breakdown strength relative to the unfilled host polymer, whilst CALxx and particularly AlNxx show less of a decrease. Considering the water uptake data shown in Figure 1, the former set of samples all absorb appreciable water following wet conditioning whereas AlNxx shows much less water absorption with CALxx absorbing an intermediate amount. The conditioning results would appear

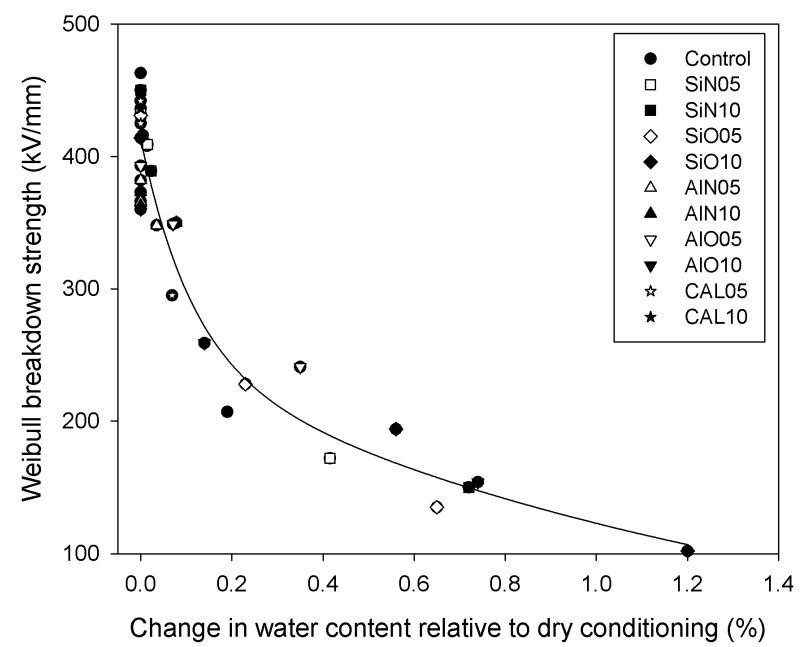

Figure 7. Plot of breakdown strength against water content (relative to dry conditioning) with double exponential fitted line.

to reinforce the correlation between reductions in electrical breakdown strength and water uptake.

\subsection{BREAKDOWN STRENGTH AND WATER CONTENT}

To test the hypothesis that variations in nanoparticle surface chemistry and consequent water uptake exerts a major influence on breakdown strength, the mass measurements from dried samples were used as a reference point to estimate the percentage water present within the various systems. This was plotted against breakdown strength, each composite yielding 3 data points, as shown in Figure 7 . Whilst this approximation is crude in that we cannot be sure that $14 \mathrm{~d}$ drying has extracted all of the water from the various materials, the correlation is nevertheless very reasonable. The variation can be described by a double exponential function of the form:

$$
y=a e^{-b x}+c e^{-d x}
$$

where $y$ is the breakdown strength, $x$ is the change in water content relative to dry conditioning and $a, b, c$ and $d$ are constants. Although this fit is at best empirical, it does nevertheless serve to demonstrate the overall trend in the data and it is notable that such a dependence holds over a range of systems exhibiting very different nanoparticle dispersions and aggregation states.

\section{DISCUSSION}

From the results presented above, we highlight some findings that we believe to be of general significance. First, the interfaces that are a critical feature of composites and nanocomposites can, particularly in non-polar matrix polymers, become sinks for water molecules. In the case of polyethylene, as considered here, although the solubility of water is low, the rate of diffusion is high and, consequently, water is readily partitioned to polar nanoparticle surfaces. This has a major effect on the electrical properties of the resulting material and, as a result, small changes in water content can manifest themselves as major changes in electrical performance. From a research perspective, this means that 
identical nanocomposites can exhibit great differences in properties, simply as a consequence of differences in environmental exposure. Technologically, the exposure of many nanodielectrics to environmental water would seem to have severe practical consequences. Second, particle surface chemistry is key in defining the interactions that will occur with water and, therefore, the propensity for water molecules to accumulate at the particle/matrix interface. Ultimately, this will be determined by the free energy of water molecules accumulated at such interfaces compared with those dispersed within the matrix polymer and, as such, substitution of polar surface moieties (e.g. hydroxyl groups) with non-polar species (e.g. alkyl chains) would be expected to reduce the local accumulation of water molecules markedly and, thereby, improve properties. This potential mechanism has little to do with increased particle/matrix interactions and improved particle dispersion and is entirely associated with surface chemistry per se. Finally, comparison of the unfilled reference, SiO10, SiN10 and CAL10 in the absence of water effects (i.e. after prolonged vacuum drying) is significant. The composites all differ significantly with respect to the aggregation state of the filler, yet all exhibit comparable breakdown strength.

While particle dispersion is accepted as being an important factor in influencing many of the macroscopic physical properties of nanocomposites, the above implies that it may not be as dominant as has been portrayed where electrical parameters are concerned. Ideally, this study would have employed four fillers with identical particle sizes and dispersion characteristics, such that the various systems would only differ in regards to their surface chemistry and hence, interactions with water. However, this investigation was limited to commercial materials and, therefore, employed four fillers with nominally comparable characteristics; such fillers do, however, contain a broad range of agglomeration states, which is likely to reflect, their particular manufacturing route. While the silicon nitride approaches an ideal dispersion, the silica contains a broad size range of structural entities, including micron-scale aggregates. The question then becomes, whether the overall behavior is dominated by the aggregates or by the nano-particulate fraction. Recently Li. et. al. [26] reported, at least as far as AC breakdown strength was concerned, that agglomerates of less than $3 \mu \mathrm{m}$ in size have no significantly negative impact. Nevertheless, the broad range of dispersion characteristics exhibited by the four fillers used in the study reported here does have one beneficial consequence; it has allowed us to contrast the impact of such structural factors with that of water absorption. The latter appears to be a critical variable and, indeed, elsewhere [34], we have shown that the good dispersion that characterizes systems based upon silicon nitride is actually detrimental, in that exposure to water allows a percolating network of water shells to form. More recent work [42] has shown the same effects in well-dispersed silica systems. Also, from a technological perspective, agglomerates will be present in many bulk prepared commercial nano-powders - such as those used here. The reliable preparation of composites that are truly free of aggregates is therefore likely to involve solvated nano-particles that are introduced into the host polymer via suspension in some suitable solvent, not from a dry powder. It is only relatively recently that such suspensions of nanoparticles have become commercially available in a range of different solvents, thereby providing compatibility with a spectrum of organic polymers. However the target application envisaged in this work, namely high voltage DC cables, are prepared by bulk melt extrusion and the addition of large volumes of solvent-suspended nanomaterial would be impractical and/or costly. As such, it would seem more practicable, initially, to consider the use of nano-powders for related investigations, despite the potential drawbacks.

\section{CONCLUSIONS}

A range of composites was prepared employing a common polymeric matrix material. The level of nanoparticle dispersion was characterized by scanning electron microscopy, the water absorption/desorption was determined and the DC dielectric breakdown strength was measured following dry, ambient and wet conditioning.

1 Composites employing silicon nitride offered excellent particle dispersion, being free of large scale aggregates. These were found to be dry when ambient conditioned but water was nevertheless absorbed after wet conditioning. The breakdown strength was identical after ambient and dry conditioning (being comparable to the unfilled host material) but fell markedly after wet conditioning.

2 Composites employing aluminum nitride offered a visually intermediate level of particle dispersion, but with included micron scale particulates. As with silicon nitride, these samples remained dry when stored under ambient conditions but, relative to SiNxx, absorbed much less water during wet conditioning. The breakdown strength approached that of the host matrix when dry or ambient conditioned but was reduced somewhat by wet conditioning.

3 Composites employing silica or alumina were found to have poor particle dispersion, with many large micronscale aggregates. These were found to exhibit an intermediate hydration state when stored under ambient conditions and could absorb/evolve a significant amount of water on subsequent conditioning. The breakdown strength was significantly less than that of the host matrix after ambient conditioning but this could be improved through dry conditioning to levels approaching that of the host polymer. As with the other systems, the breakdown strength was degraded by wet conditioning.

4 A portion of the supplied silica was calcined to change its surface chemistry. Whilst this did not affect the observed morphologies of its composites, their water absorption was dramatically reduced. Consequently its nanocomposites had an enhanced breakdown strength following ambient or dry conditioning.

The recurring theme that runs throughout this work is the critical role played by absorbed water molecules and how changes in particle surface chemistry influence this and, thereby, breakdown strength. Where systems were treated such that water effects were removed, the measured 
breakdown strength appeared largely independent of the dispersion state of the particles, within the structural range seen here.

\section{ACKNOWLEDGMENT}

The authors gratefully acknowledge the RCUK's Energy Programme for the financial support of this work through the Top \& Tail Transformation programme grant, EP/I031707/1 (http://www.topandtail.org.uk/).

\section{REFERENCES}

[1] T. Tanaka, "Dielectric nanocomposites with insulating properties", IEEE Trans. Dielectr. Electr. Insul., Vol. 12, No. 5, pp. 914-928, 2005.

[2] G. Iyer, R. S. Gorur, R. Richert, A. Krivda and L. E. Schmidt, "Dielectric Properties of Epoxy based Nanocomposites for High Voltage Insulation", IEEE Trans. Dielectr. Insul., Vol. 18, No. 3, pp. 659- 666, 2011.

[3] J-J. Park, "Effect of Nanosilica on the Mechanical Properties and AC Electrical Breakdown Strength of Epoxy/Microsilica/Nanosilica Composite", Trans. Electr. Electron. Mater., Vol. 13, No. 6, pp. 301304, 2012.

[4] R. Kochetov, I.A. Tsekmes,T. lizuka, K. Tatsumi and T. Tanaka, "The Effect of Nanosilica on the DC Breakdown Strength of Epoxy based Nanocomposites", In 2014 Ann. Rep. Conf. Electr. Insul. Dielectr. Phenomena, Des Moines, USA, pp. 715-718, 2014.

[5] C. Zou and J. C. Fothergill, "The effect of water absorption on the dielectric properties of epoxy nanocomposites", IEEE Trans. Dielectr. Electr. Insul., Vol. 15, No. 1, pp. 106-117, 2008.

[6] M. Roy, J. K. Nelson, R.K. MacCrone, L.S. Schadler, C.W. Reed, R. Keefe and W. Zenger, "Polymer Nanocomposite Dielectrics - The Role of the Interface", IEEE Trans. Dielectr. Electr. Insul., Vol. 12, No. 4, pp. 629-643, 2005.

[7] L. Zhang, Y. Zhou, X. Cui, Y. Sha, T. H. Le, Q. Ye and J. Tian, "Effect of Nanoparticle Surface Modification on Breakdown and Space Charge Behavior of XLPE/SiO2 Nanocomposites", IEEE Trans. Dielectr. Electr. Insul. Vol. 21, No. 4, pp. 1554-1564, 2014.

[8] K. Y. Lau, A. S. Vaughan, G. Chen, I. L. Hosier and A. F. Holt, "On the dielectric response of silica-based polyethylene nanocomposites", J. Phys. D: Appl. Phys., Vol. 46, No. 9, Art. No. 095303, 2013.

[9] K. Y. Lau, A. S. Vaughan, G. Chen, I. L. Hosier, A. F. Holt and K. Y. Ching, "On the space charge and DC breakdown behavior of polyethylene/silica nanocomposites", IEEE Trans. Dielectr. Electr. Insul., Vol. 21, No. 1, pp 340-351, 2014.

[10] I. L. Hosier, M. Praeger, A. F. Holt, A. S. Vaughan and S. G. Swingler, "Effect of water absorption on dielectric properties of nanosilica/polyethylene composites", In Proc. 2014 IEEE Conf. Electr. Insul. Dielectr. Phenomena, Des Moines, USA, pp.651-654, 2014.

[11] L. Hui, L. S. Schadler and J. K. Nelson, "The Influence of Moisture on the Electrical Properties of Crosslinked Polyethylene/Silica Nanocomposites”, IEEE Trans. Dielectr. Electr. Insul., Vol. 20, No. 2, pp. 641-653, 2013.

[12] C. A. Grabowski, S. P. Fillery, N. M. Westing, C, Chi, J. S. Meth, M. F. Durstock and R. A. Vaia, "Dielectric Breakdown in Silica-Amorphous Polymer Nanocomposite Films: The Role of the Polymer Matrix", Appl. Mater. Interf., Vol. 5, No. 12, pp. 5486-5492, 2013.

[13] M. Praeger, A. S. Vaughan and S. G. Swingler, "The breakdown strength and localized structure of polystyrene as a function of nanosilica fill fraction", Int'l. Conf. Solid Dielectr., IEEE, Bologna, Italy, pp. 863-866, 2013.

[14] W. Zhou, C. Wang, T. Ai, K. Wud, F. Zhao and H. Gu, "A novel fiberreinforced polyethylene composite with added silicon nitride particles for enhanced thermal conductivity", Composites Part A: Appl. Sci. Manuf., Vol. 40, No. 6-7, pp. 830-836, 2009.

[15] G. C. Xu, J. Wang, X. L. Ji, J. Y. Xiong and F. Li, "Effect of Nanosilicon Nitride on the Mechanical and Electric Properties of Polypropylene Nanocomposite", J. Comp. Mater., Vol. 41, No. 18, pp. 2213-2223, 2007.

[16] P. Preetha, M. J. Thomas, "AC breakdown characteristics of epoxy nanocomposites", IEEE Trans. Dielectr. Electr. Insul., Vol. 18, No. 5, pp. 1526-1534, 2011.
[17] A. Mohanty and V. K. Srivastava, "Dielectric breakdown performance of alumina/epoxy resin nanocomposites under high voltage application", Mat. Des., Vol. 47, pp. 711-716, 2013.

[18] N. Jaeverberg, B. Venkatesulu, H. Edin and H. Hillborg, "Prebreakdown Current and DC Breakdown Strength of Alumina-filled Poly(ethyleneco-butyl acrylate) Nanocomposites: Part I - Breakdown Strength", IEEE Trans. Dielectr. Electr. Insul., Vol. 21, No. 5, pp. 2127-2134, 2014.

[19] X. Wu, P. Jiang Y. Zhou J. Yu, F. Zhang, L. Dong and Y. Yin, "Influence of Alumina Content and Thermal Treatment on the Thermal Conductivity of UPE/Al2O3 Composite", J. Appl. Polym. Sci., Vol. 131, No. 15, Art. No. 40528, 2014.

[20] S. Choi and J. Kim, "Thermal conductivity of epoxy composites with a binary-particle system of aluminum oxide and aluminum nitride fillers", Composites Part B: Engineering, Vol. 51, pp. 140-147, 2013.

[21] S. Yu, P. Hing and X. Hu, "Thermal conductivity of polystyrenealuminium nitride composite". Composites Part A-Appl. Sci. Manuf., Vol. 33, No. 2, pp. 289-292, 2002.

[22] J. Gu, Q. Zhang, J. Dang, J. Zhang and Z. Yang, "Thermal Conductivity and Mechanical Properties of Aluminum Nitride Filled Linear LowDensity Polyethylene Composites", Polym. Engin. Sci., Vol. 49, No. 5, pp. 1030-1034, 2009.

[23] J. A. Pilgrim, P. L. Lewin and A. S. Vaughan, "Quantifying the Operational Benefits of New HV Cable Systems in terms of Dielectric Design Parameters", In Conf. Rec. 2012 IEEE Intern. Symp. Electr. Insul., San Juan, Puerto Rico, pp. 261-265, 2012.

[24] A. S. Vaughan, S. G. Swingler and Y. Zhang, "Polyethylene Nanodielecterics: the Influence of Nanoclays on Structure Formation and Dielectric Breakdown", Trans. IEE Japan, Vol. 126, pp. 1057-1063, 2006.

[25] T. Andritsch, R. Kochetov, Y. T. Gebrekiros, P. H. F. Morshuis and J. J. Smit, Short term DC Breakdown Strength in Epoxy based BN Nanoand Microcomposites, IEEE Int'l. Conf. Solid Dielectr., IEEE, Piscataway, USA, pp. 1-4, 2010.

[26] W. Li, H. Hillborg and U. W. Gedde, Influence of Process Conditions and Particle Dispersion on the AC Breakdown Strength of Polyethylenealuminium Oxide Nanocomposites, IEEE Trans. Dielectr. Electr. Insul., Vol. 22, No. 6, pp. 3536-3542, 2015

[27] S. I. Raider, R. Flitsch, J. A. Aboaf and W. A. Pliskin, "Surface Oxidation of Silicon Nitride Films", J. Electrochem. Soc., Vol. 123, No. 4, pp. 560-565, 1976.

[28] E. W. Osborne and M. G. Norton, "Oxidation of aluminium nitride", J. Mat. Sci., Vol. 33, No. 15, pp. 3859-3865, 1998.

[29] L. T. Zhuravlev, "Concentration of hydroxyl-groups on the surface of amorphous silicas", Langmuir, Vol. 3, No. 3, pp. 316-318, 1987.

[30] L. T. Zhuravlev, "The surface chemistry of amorphous silica. Zhuravlev model", Colloids and Surfaces A - Physicochemical and Engineering Aspects, Vol. 173, No. 1-3, pp. 1-38, 2000.

[31] M. Praeger, I. L. Hosier, A. S. Vaughan and S. G. Swingler, "The effects of surface hydroxyl groups in polyethylene-silica nanocomposites", In Proc. 2015 IEEE Electr. Insul. Conf., IEEE, Seattle, USA, pp. 201-204, 2015.

[32] I. L. Hosier, A. S. Vaughan, and S. G. Swingler, "The effects of measuring technique and sample preparation on the breakdown strength of polyethylene", IEEE Trans. Dielectr. Electr. Insul., Vol. 9, No. 3, pp. 353-361, 2002.

[33] S. N. Kolesov, "The influence of morphology on the electric strength of polymer insulation", IEEE Trans. Electr. Insul., Vol. 15, No. 5, pp. 382388,1980

[34] I. L Hosier, M. Praeger, A. S. Vaughan and S. G Swingler, "The effects of water on the dielectric properties of silicon based nano-composites", IEEE Trans. Nanotech., 16, 2, pp. 169-179, 2017.

[35] I. L Hosier, M. Praeger, A. S. Vaughan and S. G Swingler, "The effects of water on the dielectric properties of aluminum based nanocomposites", submitted to IEEE Trans. Nanotech.

[36] R. H. Olley and D. C. Bassett, "An improved permanganic etchant for polyolefins", Polymer, Vol. 23, No. 12, pp. 1707-1710, 1982.

[37] Z. G. Wu, Y. X. Zhao, L. P. Xu and D. S. Liu, Preparation of zirconia aerogel by heating of alcohol-aqueous salt solution, Journal of NonCrystalline Solids, Vol. 330, No. 1-3, pp. 274-277, 2003.

[38] M. M. Ba-Abbad, A. A. H. Kadhum, A. B. Mohamad, M. S. Takriff, and $\mathrm{K}$. Sopian, The effect of process parameters on the size of $\mathrm{ZnO}$ nanoparticles synthesized via the sol-gel technique, J. Alloys Comp., Vol. 550, pp. 63-70, 2013. 
[39] Q. Lei, S. Sheng, "Effect of temperature and humidity on electrical breakdown characteristics of low-density polyethylene film for the various stressing modes", IEEE 2nd Int'l. Conf. Prop. Appl. Dielectr. Mater., Beijing, China, pp. 590-593, 1988.

[40] G. Gao, W. Kalkner, "Effect of water content and temperature on the electrical breakdown strength of XLPE-insulated cables", 7th Int'l. Sympos. High Voltage Engin., Dresden, Germany, pp. 251-254, 1991.

[41] D. L. Ma, R. W. Siegel, J. I. Hong, L. S. Schadler, E. Martensson and C. Onneby, "Influence of nanoparticle surfaces on the electrical breakdown strength of nanoparticle-filled low-density polyethylene", J. Mat. Res., Vol. 19, No. 3, 857-863, 2004

[42] S. Virtanen, A. S. Vaughan, F. Saiz and N. Quirke, "Electrical Conductivity and Moisture Uptake Studies of Low Density Polyethylene Octylnanosilica Composite" Submitted to 25th Nordic Insul. Sympos. Mat. Comp. Diag., 2017.

All data published in this paper are openly available from the University of Southampton repository at http://dx.doi.org/10.5258/SOTON/D0026

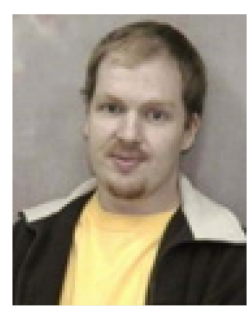

Ian Hosier received the B.Sc. degree in physics and the $\mathrm{Ph} . \mathrm{D}$. degree in polymer physics from The University of Reading, UK. He then went on with postdoctoral research at the same university. In 2001 he accepted a placement at Florida State University in the USA looking at atomic force microscopy of semicrystalline polymer blends. In 2003 he returned to the UK to take a research post at the University of Southampton looking at the aging behavior of a variety of solid and liquid insulation materials. Research interests include dielectrics, ageing, microscopy and polymer morphology.

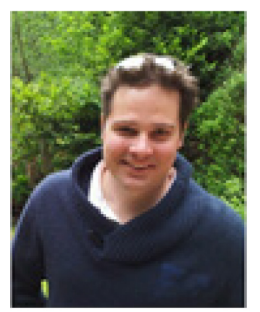

Matthew Praeger has an M.Phys degree in Physics with Laser Science and received a Ph.D for Laser Generation of X-rays; both were awarded by the University of Southampton. He subsequently worked at the Optoelectronics Research Centre on laser beam characterization but then shifted focus to applications, developing microfluidic and electrohydrodynamic devices. Since moving to the Electrical and Electronic Engineering group he has pursued interests in electrical phenomena such as dielectrophoresis and in nanocomposite materials for dielectric applications.

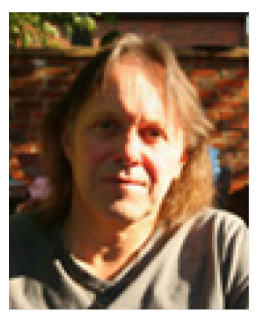

Alun Vaughan (SM'07) has a B.Sc. degree in chemical physics and a Ph.D. degree in polymer physics. After working at the UK's Central Electricity Research Laboratories and spending a period as an academic at The University of Reading, he is now Professor of Dielectric Materials at the University of Southampton. He is a former chair of The Dielectrics Group of the Institute of Physics, a Fellow of the Institute of Physics and a Fellow of the IET and delivered the IEEE DEIS 2016 Eric O.

Forester Memorial Lecture.

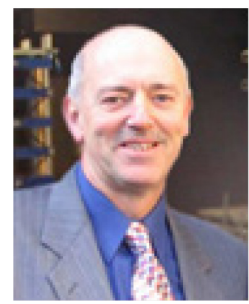

Steve Swingler received the B.A. and Ph.D. degrees in physics from the University of Lancaster. In 1976 he was appointed Pirelli Postdoctoral Research Fellow at Southampton University, investigating dielectrics for superconducting and extruded dc cables. He joined the Central Electricity Research Laboratories at Leatherhead in 1979 working mainly on novel cable systems and insulating materials. In 1990 he transferred to the National Grid Company, becoming Cables Manager and then Company Undergrounding Adviser. In 2003 he joined the School of Electronics \& Computer Science at Southampton University as Professor in Transmission Asset Engineering and retired in 2015. 